Original Research Paper

\title{
Distribution Pattern of Human Urinary Schistosomiasis in Kwara State, Nigeria
}

\author{
${ }^{1,2}$ Sunday Ojo Joseph, ${ }^{2}$ Babamale Olarewaju Abdulkareem and ${ }^{2}$ Ugbomoiko Uade Samuel \\ ${ }^{I}$ Department of Bioscience and Biotechnology, Kwara State University, Malete, Nigeria \\ ${ }^{2}$ Department of Zoology, Parasitology Unit, University of Ilorin, Ilorin, Nigeria
}

Corresponding Author:

Babamale Olarewaju

Abdulkareem

Parasitology Unit, Department of Zoology, University of

Ilorin, Ilorin, Nigeria

Email: olas4nice2004@yahoo.co.uk

\begin{abstract}
Human urinary schistosomiasis is a severe parasitic infectious disease in many rural communities in tropical Africa. The status of infection in Kwara State is inadequately documented. We, therefore, investigated distribution pattern of infection amongst school-aged children in the three Senatorial Districts of the state. Of 3757 urine samples examined, $670(17.8 \%)$ were infected with $8.9 \%$ in Central, $13.5 \%$ in South and $28.7 \%$ in the North Senatorial districts. The overall geometric mean intensity and mean population egg load were 347.3 and 61.9 eggs per $10 \mathrm{~mL}$ urine respectively. Generally, infection is age and sex dependent $(\mathrm{p}<0.05)$. Males had significantly higher prevalence and intensity of infections than the female $(20.6 \%, 361 \mathrm{eggs} / 10 \mathrm{~mL}$ of urine vs. $14.3 \%, 340 \mathrm{eggs} / 10 \mathrm{~mL}$ of urine; $\mathrm{p}<0.0001)$. A high eggcounts of 412.25 eggs $/ 10 \mathrm{~mL}$ urine was recorded among 16-20 years age group in Kwara central. In this study, 27.2 and 10.7\% were moderately and heavily infected respectively. There is a significant association between intensity of infection and prevalence of haematuria and proteinuria among the infected population $(\mathrm{p}<0.0001)$. Our findings show that urinary schistosomiasis is endemic among kwaran schoolchildren and further study is recommended to reveal the essentials attributable risk factors of infection in the endemic communities.
\end{abstract}

Keywords: Schistosoma haematobium, Kwara State, Districts, Haematuria, Proteinuria

\section{Introduction}

Human urinary schistosomiasis is a water-dependent urogenital disease caused by the blood flukes (Schistosoma haematobium), acquired from freshwater bodies containing infected intermediate snail hosts, Bulinus species. The disease is of a major public health significance in many resource-constrained communities in sub-Saharan Africa (Adenowo et al., 2015; Birma et al., 2017; Houmsou et al., 2016). It is ranked second to malaria with regard to its prevalence and population at risk. Global estimate shows that approximately 230 million people are infected, with annual loss of 1.7-4.5 million Disability Adjusted Life Years (DALYs) (Boko et al., 2016; Colley et al., 2014; Njunda et al., 2017).

Transmission of urinary schistosomiasis is dependent on a wide range of socio-cultural and environmental factors including water developmental projects such as dam construction and irrigation schemes (Jamison et al.,
2006). Haematuria is a classical symptom of human urogenital schistosomiasis and egg-induced inflammatory responses are characterised by T-helper-2 lymphocytes and other polymorphonuclear leukocytes (Grimes et al., 2014). Other severe pathological conditions include fibrosis of the bladder and urethral, hydronephrosis and possibly bladder cancer (Mostafa et al., 1999).

In endemic settings, chronic infection is common due to repeated exposure to infective stage, cercaria. Studies in many endemic regions have identified schoolchildren and young adults as the most susceptible groups. Eggs excretion reached a peak at this age group and decreased to relatively low levels in adulthood (Adenowo et al., 2015; Colley et al., 2014). In Nigeria, urinary schistosomiasis is widespread in the poor and marginalized communities, with varying prevalences, in all the cardinal zones of the country (Engels et al., 2002; Omonijo et al., 2013; Ugbomoiko et al., 2010) apart from the earlier studies 
(Bello and Edungbola, 1992; Edungbola et al., 1988) in some selected locations in old Kwara State, information on the epidemiology of the disese is limited in our study area. Adequate data on the currenrt infection status are necessary for the planning and implementation of control strategies. This study is therefore conducted to bridge the gap on the current status of urinary schistosomiasis among the schoolchildren in Kwara State, North central Nigeria.

\section{Materials and Methods}

\section{Study Area and Population}

The study was carried out in Kwara state $\left(8^{\circ}\right.$ and $10^{\circ} \mathrm{N}$ latitudes and $3^{\circ}$ and $6^{\circ} \mathrm{E}$ longitudes), with a total land mass of $32,500 \mathrm{~km}^{2}$. Kwara State comprises of 16 administrative local government areas in three distinct senatorial (north, central and south) zones. The climate is tropical, with an annual rainfall range of 1000-1.500 $\mathrm{mm}$ and average maximum temperature of $30-35^{\circ} \mathrm{C}$ but the natural vegetation is a derived savannah in the North and rain forest in the South. Generally, the sanitation condition in many of our study locations is precarious. Besides, portable water supply, electricity and toilet facilities were inadequately. During the dry months (November to April) inhabitants depend predominantly on natural water from the stream or pond for their household use.

Preliminary school-to-school visits were made to recruit schoolchildren of $\leq 20$ years in the three randomly selected communities in each of the 16 local government areas. All volunteers were enlisted except the menstrating females and individuals who had stayed for less than 3 months in the community. Approximately 2985 school children, across the three senatorial districts of the state, were estimated to be sufficient for the investigation considering $80 \%$ power at $95 \%$ confident interval.

\section{Data collection and Processing}

Informed consent was obtained from the parents through Parent Teacher Association (PTA), community leaders and State Ministry of Health and Education after thorough explanation of the research protocol. All the consented schoolchildren were trained on how to handle urine sample before pre-labelled, wide-mouthed, screw-capped plastic containers were given to obtain their full bladder mid-day urine. At the point of submission of the urine sample, individual bio-data were obtained and the microhaematuria and proteinuria were immediately assessed using commercial reagent strips (Medi-test Combur-9; Analytic on Biotechnologies, Lichtenfels, Germany). Thereafter, the samples were transported to laboratory at the
Department of Bioscience and Biotechnology, Kwara State University, Malate for the parasitological examination of $S$. haematobium ova. A $10 \mathrm{~mL}$ of each urine sample was filtered through a $12 \mu \mathrm{m}$ polycarbonate filter (Millipore) and examined on $\times 100$ light compound microscope. Intensity of infection was classified as heavy (>500 eggs/10 mL), moderate (51499 eggs $/ 10 \mathrm{~mL})$ or light $(50 \mathrm{eggs} / 10 \mathrm{~mL})$ according to the guidelines of World Health Organisation. Randomly selected samples in each district were examined by an independent team of parasitologists for the purpose of quality control.

\section{Ethical Considerations}

The study protocol was approved by the University of Ilorin Research and Ethical Committee (Ref. No. UERC/ASN/2014/011), the Joint committee of Kwara State Ministry of Health and Education (Ref. No. $\mathrm{MOH} / \mathrm{KS} / \mathrm{ECI} / 777 / 58)$ and the ad-hoc ethical committee of each Local-Government Authorities before the commencement of the study. Also, informed written consent was obtained from each volunteer and/or the caregivers before the subjects were enrolled in the study.

\section{Statistical Analysis}

Statistical analysis was performed using IBM.SPSS 21.0 (International Business Machine-Statistical Package for Social Sciences) and R Core Team (R Version 3.2.22015). Prevalence of infection and comparison of proportions with respect to sex and age of the participants were determined by Chi-square and proportional test. Differences between means were tested using independent samples t-test and one way ANOVA. Analysis of geometric egg counts was based on the infected individual in the population while mean population egg density was estimated as the burden of the infection in the investigated population. Comparisons across groups were done using Fisher's exact test and $p$ values $<0.05$ were considered significant.

\section{Results}

Of the 3757 schoolchildren enrolled in the study, $670(17.8 \%)$ were infected with urinary schistosomiasis (Fig. 1). The occurrence of infection statistically varies with location; in the north $(28.7 \%)$, central $(8.9 \%)$ and south $(13.5 \%)(p<0.0001)$. There was a variation in the intensity of eggcount, with overall geometric mean intensity of $347.3 \mathrm{eggs} / 10 \mathrm{~mL}$ urine and mean population egg load of 61.9 eggs/10 mL (Table 1). Table 2 revealed that the males had higher infection and egg intensity than their female counterparts $(20.6 \%, 361 \mathrm{eggs} / 10 \mathrm{~mL}$ vs. $14.3 \%, 340 \mathrm{eggs} / 10 \mathrm{~mL}$ of urine; $\mathrm{p}<0.0001)$. Overall, the prevalence and intensity of infection varied significantly $(\mathrm{p}<0.0001)$. Infection 
is high in schoolchildren within age bracket of $6-10$ years in Kwara Central (11.8\%) and South (15.8\%) while $35.0 \%$ point prevalence was recorded among children within 16-20 year in Kwara North. The highest intensity of infection occurred in young children (6-10 years) in all the three senatorial districts (Table 3 ).

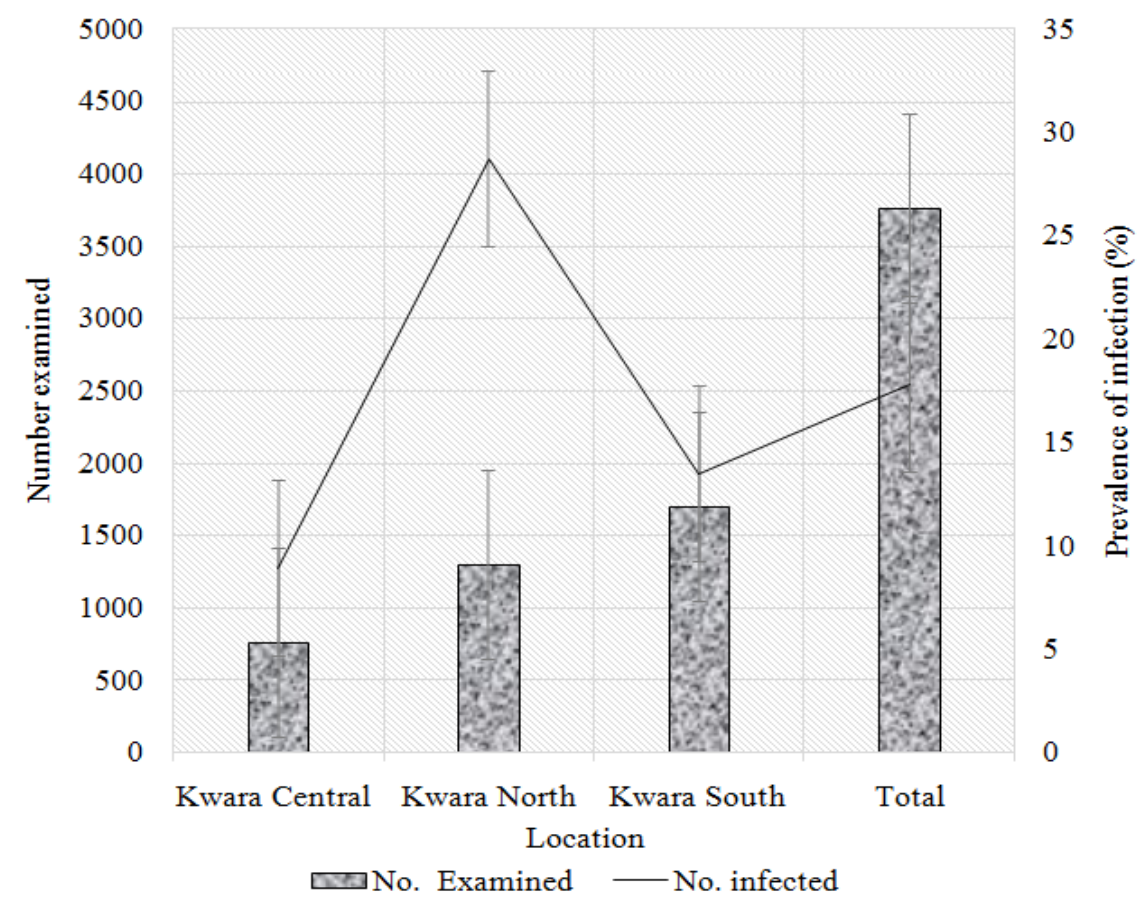

Fig. 1:Overall prevalence of infection with respect to locations; P. Value $<0.0001 ;$ Kwara Central = Asa, Ilorin East, Ilorin South, Ilorin East, Kwara North = Baruten, Edu, Moro, Patigi, Kaima; Kwara South = Ekiti, Ifelodun, Irepodun, Isin, Offa, OkeEro, Oyun

Table 1: Intensity of urinary schistosomiasis amongst schoolchildren in Kwara State

\begin{tabular}{|c|c|c|c|c|c|}
\hline \multirow[b]{2}{*}{ Senatorial district } & \multirow[b]{2}{*}{ t Number examined } & \multicolumn{2}{|c|}{ Geometric mean intensity } & \multicolumn{2}{|c|}{ Mean population egg density } \\
\hline & & $\mathrm{X} \pm \mathrm{SD}$ & $95 \% \mathrm{CI}$ & $\mathrm{X} \pm \mathrm{SD}$ & $95 \% \mathrm{CI}$ \\
\hline Kwara central & 757 & $367.07 \pm 247.77$ & $306.64-427.51$ & $32.49 \pm 127.45$ & $23.39-41.58$ \\
\hline Kwara North & 1301 & $351.76 \pm 256.96$ & $325.60-377.93$ & $100.85 \pm 210.28$ & $89.41-112.29$ \\
\hline Kwara South & 1699 & $334.31 \pm 269.37$ & $299.31-369.31$ & $45.26 \pm 151.24$ & $38.06-52.45$ \\
\hline Total & 3757 & $347.31 \pm 260.22$ & $327.56-367.04$ & $61.94 \pm 171.45$ & $56.42-67.45$ \\
\hline P. value & & $<0.0001$ & & $<0.0001$ & \\
\hline
\end{tabular}

Table 2: Prevalence and intensity of urinary schistosomiasis stratified with sex of schoolchildren in Kwara State

\begin{tabular}{|c|c|c|c|c|c|c|}
\hline \multirow[b]{2}{*}{ Senatorial district } & \multirow[b]{2}{*}{ Gender } & \multicolumn{3}{|l|}{ Prevalence } & \multicolumn{2}{|c|}{ Intensity geometric mean intensity } \\
\hline & & No. Examined & Nu. Infected (\%) & $95 \% \mathrm{CI}$ & $\mathrm{X} \pm \mathrm{SD}$ & $95 \% \mathrm{CI}$ \\
\hline \multirow[t]{3}{*}{ Kwara central } & $\mathrm{M}$ & 464 & $45(9.7)$ & $7.23-12.86$ & $365.73 \pm 240.41$ & $293.51-437.96$ \\
\hline & $\mathrm{F}$ & 293 & $22(7.5)$ & $4.9-11.3$ & $369.82 \pm 268.01$ & $250.99-488.65$ \\
\hline & P. value & & 0.18 & & 0.20 & \\
\hline \multirow[t]{3}{*}{ Kwara North } & $\mathrm{M}$ & 800 & $254(31.8)$ & $28.56-35.12$ & $352.38 \pm 267.11$ & $319.37-385.38$ \\
\hline & $\mathrm{F}$ & 501 & $119(23.8)$ & $20.14-27.78$ & $350.45 \pm 307.81$ & $307.81-393.09$ \\
\hline & P. value & & 0.001 & & 0.051 & \\
\hline \multirow[t]{3}{*}{ Kwara South } & $\mathrm{M}$ & 992 & $157(15.8)$ & $13.64-18.28$ & $315.01 \pm 271.67$ & $272.19-357.84$ \\
\hline & $\mathrm{F}$ & 707 & $73(10.3)$ & $8.23-12.86$ & $375.81 \pm 261.37$ & $314.83-436.79$ \\
\hline & $P$. value & & 0.001 & & 0.001 & \\
\hline \multirow[t]{3}{*}{ Total } & $\mathrm{M}$ & 2256 & $456(20.2)$ & $18.59-21.94$ & $361.83 \pm 266.33$ & $316.32-365.35$ \\
\hline & $\mathrm{F}$ & 1501 & $214(14.2)$ & $12.55-16.15$ & $340.09 \pm 246.75$ & $327.84-394.34$ \\
\hline & P. value & & $<0.0001$ & & $<0.0001$ & \\
\hline
\end{tabular}


Table 3: Prevalence and intensity of urinary schistosomiasis stratified with age of schoolchildren in Kwara State

\begin{tabular}{|c|c|c|c|c|c|c|}
\hline \multirow[b]{2}{*}{ District } & \multirow[b]{2}{*}{ Age } & \multicolumn{3}{|l|}{ Prevalence } & \multicolumn{2}{|c|}{ Intensity geometric mean intensity } \\
\hline & & No. Examined & No. Infected (\%) & $95 \% \mathrm{CI}$ & $\mathrm{X} \pm \mathrm{SD}$ & $95 \% \mathrm{CI}$ \\
\hline \multirow[t]{5}{*}{ Kwara central } & $3-5$ & 61 & $2(3.3)$ & $0.57-12.36$ & $89.50 \pm 116.67$ & $-958.76-1137.76$ \\
\hline & $6-10$ & 338 & $40(11.8)$ & $8.68-15.88$ & $412.25 \pm 240.78$ & $278.75-431.60$ \\
\hline & $11-15$ & 323 & $21(6.5)$ & $4.17-9.91$ & $407.57 \pm 267.83$ & $285.66-529.49$ \\
\hline & $16-20$ & 35 & $4(11.4)$ & $3.73-27.68$ & $355.18 \pm 238.98$ & $29.12-795.38$ \\
\hline & P. value & & 0.071 & & 0.022 & \\
\hline \multirow[t]{5}{*}{ Kwara North } & $3-5$ & 79 & $8(10.1)$ & $4.78-19.50$ & $92.63 \pm 109.95$ & $0.70-184.55$ \\
\hline & $6-10$ & 549 & $163(29.7)$ & $25.93-33.74$ & $391.02 \pm 260.64$ & $350.7-431.33$ \\
\hline & $11-15$ & 496 & $140(28.2)$ & $24.34-32.45$ & $319.94 \pm 232.89$ & $281.03-358.86$ \\
\hline & $16-20$ & 177 & $62(35.0)$ & $28.12-42.60$ & $353.85 \pm 286.38$ & $281.13-426.56$ \\
\hline & P. value & & 0.01 & & 0.01 & \\
\hline \multirow[t]{5}{*}{ Kwara South } & $3-5$ & 107 & $7(6.5)$ & $2.89-13.48$ & $118.57 \pm 99.05$ & $27.01-210.14$ \\
\hline & $6-10$ & 692 & $109(15.8)$ & $13.16-18.73$ & $373.58 \pm 259.71$ & $324.27-422.89$ \\
\hline & $11-15$ & 639 & $80(12.5)$ & $10.1-15.40$ & $326.11 \pm 277.55$ & $264.35-387.88$ \\
\hline & $16-20$ & 261 & $34(13.0)$ & $9.31-17.87$ & $272.12 \pm 278.33$ & $175.00-369.23$ \\
\hline & P. value & & 0.13 & & 0.034 & \\
\hline \multirow[t]{5}{*}{ Total } & $3-5$ & 247 & $17(6.9)$ & $4.18-21.83$ & $102.94 \pm 99.99$ & $51.53-154.35$ \\
\hline & $6-10$ & 1579 & $312(19.8)$ & $17.84-21.82$ & $380.33 \pm 257.15$ & $351.68-408.98$ \\
\hline & $11-15$ & 1458 & $290(19.9)$ & $17.89-22.05$ & $329.63 \pm 251.67$ & $297.69-361.56$ \\
\hline & $16-20$ & 474 & $47(9.9)$ & $7.45-13.05$ & $328.40 \pm 282.65$ & $272.32-384.48$ \\
\hline & P. value & & $<0.0001$ & & $<0.0001$ & \\
\hline
\end{tabular}

Table 4: Prevalence of haematuria and proteinuria stratified with egg intensity in schoolchildren in Kwara State

\begin{tabular}{|c|c|c|c|c|c|c|c|c|c|c|}
\hline \multirow{2}{*}{$\begin{array}{l}\text { Egg counts } \\
/ 10 \mathrm{~mL} \text { of urine }\end{array}$} & \multirow{2}{*}{$\begin{array}{l}\text { Number } \\
\text { examined (\%) }\end{array}$} & \multicolumn{5}{|c|}{$\%$ with Haematuria at $\left(\times 10^{6}\right.$ erythrocytes $\left.1^{-1}\right)$} & \multicolumn{4}{|c|}{$\%$ with Proteinuria at $\left(\mathrm{g}^{-1}\right)$} \\
\hline & & 0 & ${ }^{+} 1$ & ${ }^{+} 2$ & +3 & Gh & 0 & ${ }^{+} 1$ & ${ }^{+} 2$ & +3 \\
\hline 0 & $3088(82.2)$ & 99.70 & 0.23 & 0.097 & 0.00 & 0.00 & 99.87 & 0.097 & 0.032 & 0.00 \\
\hline $1-49$ & $416(62.1)$ & 37.62 & 58.42 & 3.960 & 0.00 & 0.00 & 54.46 & 42.540 & 2.970 & 0.00 \\
\hline $50-499$ & $182(27.2)$ & 27.18 & 17.42 & 29.27 & 19.16 & 6.97 & 32.75 & 19.160 & 29.270 & 18.82 \\
\hline$\geq 500$ & $72(10.7)$ & 0.00 & 2.24 & $\begin{array}{l}36.54 \\
p<0.0001\end{array}$ & 41.35 & 10.26 & 6.73 & 10.260 & 36.220 & $\begin{array}{l}36.86 \\
p<0.0001\end{array}$ \\
\hline
\end{tabular}

Key: Gh $=$ Gross haematuria

In this study, $27.2 \%$ of moderate and $10.7 \%$ of heavy infections were recorded amongst the infected population. There was a significant correlation between intensity of infection and prevalence of haematuria and proteinuria $(p<0.0001)$. Table 4 showed that haematuria increases with intensity of infection, approximately $41.4 \%$ of infected children had haematuria with egg count of $\geq 500$. Similar trend was observed with prevalence of proteinuria with intensity of infection.

\section{Discussion}

The high prevalence and intensity of infection observed in this study confirmed a sustained longterm endemicity of urogenital schistosomiasis in Kwara state and the morbidity of the disease in Nigerian schoolchildren is grave (Ugbomoiko et al., 2010; Uneke et al., 2007). In our study area, activities such as laundry, fetching of water for domestic use and bathing/swimming in freshwater bodies are daily activities of schoolchildren that increase the risk of infection. In addition, occupational activities of the parents (e.g., fishing) and the behaviour of urinating in water bodies may help to maintain infection status (Ugbomoiko et al., 2010). This scenerio increases morbidity that may negatively impact on the affected children's wellbeing. The common morbidities associated with this infection, as previously reported by many researchers both within and outside Nigeria, include growth retardation, impairment of memory and cognitive reasoning, increased risk of anaemia, malnutrition and dismal learning capacity (Friedman et al., 2005; Gray et al., 2011).

In this study, prevalence of infection varies from $8.9 \%$ to $28.7 \%$. This is similar to many reports in Nigeria (Atalabi et al., 2017; Uchendu et al., 2017) and other countries (Dahab and El-Bingawi, 2012; Negussu et al., 2013). The reports from Sokoto, Nigeria (Singh et al., 2016), Ethiopia (Geleta et al., 2015) and Senegal (Senghor et al., 2014) revealed considerable 
higher prevalent rates. The difference in the occurrence of infection may be attributed to the different environmental factors.

Although prevalence rates are uneven, infection was generally observed in all the three senatorial districts. The high burden of infection recorded in the poorresource communities in Kwara North when compared with those from Kwara central particularly in Ilorin metropolis reflects the unequal distribution of infrastructural facilities and water supply in the state. Several reports have showed that transmission of waterborne parasites is limited in urban cities with available portable pipe-borne water than in rural areas. Unavailability of water supply in rural areas probably increases contact with the contaminated natural water bodies. This finding therefore shows the importance of portable water supply in the control and prevention of urinary schistosomiasis. Therefore, prompt government intervention in parasite disease control must complement the mass administration of drugs programme in our endemic areas and other areas with similar epidemiological conditions in the sub-Saharan Africa for meaningful outcome. Besides, variation in risk factors, distribution of infected snail intermediate hosts and differences in water contact activites may jointly determine the variation in infection.

Age and sex patterns of infection in the current study area were similar to many reports from schistosomiasis endemic communities in Nigeria and other African countries (Ahmed et al., 2012; Garba et al., 2010; Senghor et al., 2014). Typically, the overall prevalence and intensity of infection were significantly higher in the older age groups (6-15 years) than the youngest age group ( $>5$ years). This conforms with the several reports (Njunda et al., 2017; Sady et al., 2013; Ugbomoiko et al., 2010). The intense water contact activites observed amongst these age groups possibly justified the high prevalence of infection recorded. However, the apparent socio-economic and cultural differences observed in the study groups and the age-related immunological changes may be a possible explanation for the decline of infection in the oldest age group ( $<16$ years). Although the sex-related intensity of infection was slight in this study, the prevalence was significantly higher in males than the females. A possible explanation for this could be that the male children are freer to engage in boisterous water contact activities than the females. In many of our study areas, the males were predominantly involved in assisting parents in water-related agricultural practices like fishing. Nevertheless, the pathological consequences of infection in both sexes are severe. Generally, infection is marked with haematuria, frequent urination, burning micturition and suprapubic discomfort which may, at chronic stage, results in obstructive uropathy, squamous-cell carcinoma of the bladder, infertility and increased risk of abortion in females (Khalaf et al., 2012; Wamachi et al., 2004).
As indicated in several reports, the clinical pathologies diagnosed in many patients with urinary schistosomiasis correlates with the intensity of infection (Fatiregun et al., 2009; Magnussen et al., 2001). Haematuria and proteinuria are ascribed to the histopathological alterations induced by ova and have been widely used as indicators of urinary schistosomiasis (Mafe, 1997; Ugbomoiko et al., 2010; 2009). In limited population of schoolchildren, macrohaematuria are used as biomarkers where reagent strips are unavailable (Mafe, 1997). Proteinuria due to primary involvement of the bladder and lower ureter in urinary schistosomiasis has also been previously reported in studies (Doehring et al., 1985). Our data showed that approximately $94 \%$ of our infected schoolchildren had varied levels of microhaematuria and microproteinuria. This is comparably higher to the data reported by Ugbomoiko et al. (2009) and Ekpo et al. (2010) who reported 68 and $47 \%$ respectively in our geographical area. Chronic blood loss as seen in gross macrohaematuria may lead to serious medical conditions in some infected children. A high occurrence of microhaematuria observed in our study population calls for urgent treatment.

The status of infection in this study may be underestimated due to some limitations. Firstly, only one sample was collected from each participant which may give false status of infection compared to when two or three samples were collected at different day. Secondly, analysis of risk factors which may be used for better recommendation of control and preventive strategies in this study area were not investigated. Another limitation of the study is the small fraction of study populations selected from each Local Government. It is therefore recommended that community-based studies should be conducted to determine the true prevalence of urinary schistosomiasis for better documentation of infection status.

\section{Conclusion}

The outcome of this study underscores that urogenital schistosomiasis is not only endemic in Kwara state but it is a major health challenges among schoolchildren in resources-poor communities of the state. Although, infection is prevalent in both sexes but it is significantly higher in male and younger children. Our finding in this study also indicates long term transmission of infection amongst school children with severe impact on their intellectuals and academic performance. Therefore, the on-going mass administration of Praziquantel in most schools in the state is justifiable for the reduction of parasite in infected school children. However, chemotherapy option should be supplemented with public awareness campaign and provision of portable water facilities in most rural communities to forestall reinfection and transmission to area previously not endemic. 


\section{Acknowledgment}

We acknowledged various communiy leaders and all the staff of ministry of education and health who created the enabling environment for the study. We also appreciate all our study participants for their coperation.

\section{Author's Contributions}

Sunday Ojo Joseph: Involved in the design, collection of data and in the drafting of the manuscript.

Babamale Olarewaju Abdulkareem: Drafted the manuscript and also did the statistical analysis.

Ugbomoiko Uade Samuel: Designed, supervised the work and proofread the manuscript.

\section{Ethics}

This has been provided for in the ethic consideration section of the study. However, all the authors declare no conflict of interest in the publication of this study.

\section{References}

Adenowo, A.F., B.E. Oyinloye, B.I. Ogunyinka and A.P. Kappo, 2015. Impact of human schistosomiasis in sub-Saharan Africa. Brazilian J. Infect. Dis., 19: 196-205. DOI: 10.1016/j.bjid.2014.11.004

Ahmed, A.M., H. Abbas, F.A. Mansour, G.I. Gasim and I. Adam, 2012. Schistosoma haematobium infections among schoolchildren in central Sudan one year after treatment with praziquantel. Parasites Vectors, 5: 108-108. DOI: $10.1186 / 1756-3305-5-108$

Atalabi, T.E., T.O. Adubi and U. Lawal, 2017. Rapid mapping of urinary schistosomiasis: An appraisal of the diagnostic efficacy of some questionnaire-based indices among high school students in Katsina State, northwestern Nigeria. PLoS Neglected Tropical Dis., 11: e0005518-e0005518.

DOI: 10.1371/journal.pntd.0005518

Bello, A. and L. Edungbola, 1992. Schistosoma haematobium: A neglected common parasitic disease of childhood in Nigeria. Incidence and intensity of infection. Acta Paediatrica, 81: 601-604.

Birma, J., G. Chessed, P.A. Shadrach, J.I. Nganjiwa and A.B. Yako et al., 2017. Urinary schistosomiasis in communities around Kiri Lake, Shelleng Local Government Area, Adamawa State, Nigeria. J. Applied Sci. Environ. Manage., 21: 128-134. DOI: 10.4314 jasem.v21i1.14

Boko, P.M., M. Ibikounle, A. Onzo-Aboki, J.J. Tougoue and Y. Sissinto et al., 2016. Schistosomiasis and soil transmitted helminths distribution in Benin: A baseline prevalence survey in 30 districts. PloS One, 11: e0162798-e0162798.

DOI: $10.1371 /$ journal.pone.0162798
Colley, D.G., A.L. Bustinduy, W.E. Secor and C.H. King, 2014. Human schistosomiasis. Lancet, 383: 2253-2264. DOI: 10.1016/S0140-6736(13)61949-2

Dahab, T.O. and H.M. El-Bingawi, 2012. Epidemiological survey: Schistosoma haematobium in schoolchildren of White Nile areas, Khartoum 2012. Sudan Med. J., 48: 135-140.

Doehring, E., J.H.H. Ehrich, U. Vester, H. Feldmeier and U. Poggensee et al., 1985. Proteinuria, hematuria and leukocyturia in children with mixed urinary and intestinal schistosomiasis. Kidney Int., 28: 520-525. DOI: $10.1038 /$ ki.1985.159

Edungbola, L., S. Asaolu, M. Omonisi and B. Aiyedun, 1988. Schistosoma haematobium infection among schoolchildren in the Babana district, Kwara State, Nigeria. African J. Medicine Medical Sci., 17: 187-193.

Ekpo, U.F., A. Laja-Deile, A.S. Oluwole, S.O Sam-Wobo and C.F. Mafiana, 2010. Urinary schistosomiasis among preschool children in a rural community near Abeokuta, Nigeria. Parasites Vectors, 3: 58-58.

Engels, D., L. Chitsulo, A. Montresor and L. Savioli, 2002. The global epidemiological situation of schistosomiasis and new approaches to control and research. Acta Tropica, 82: 139-146. DOI: $10.1016 / \mathrm{S} 0001-706 \mathrm{X}(02) 00045-1$

Fatiregun, A.A., K.O. Osungbade and A.E. Olumide, 2009. Cost-effectiveness of screening methods for urinary schistosomiasis in a school-based control programme in Ibadan, Nigeria. Health Policy, 89: 72-77. DOI: $10.1016 /$ j.healthpol.2008.05.004

Friedman, J.F., H.K. Kanzaria and S.T. McGarvey, 2005. Human schistosomiasis and anemia: The relationship and potential mechanisms. Trends Parasitol., 21: 386-392. DOI: 10.1016/j.pt.2005.06.006

Garba, A., N. Barkiré, A. Djibo, M.S. Lamine and B. Sofo et al., 2010. Schistosomiasis in infants and preschool-aged children: Infection in a single Schistosoma haematobium and a mixed S. haematobium-S. mansoni foci of Niger. Acta Tropica, 115: 212-219. DOI: 10.1016/j.actatropica.2010.03.005

Geleta, S., A. Alemu, S. Getie, Z. Mekonnen and B. Erko, 2015. Prevalence of urinary schistosomiasis and associated risk factors among Abobo primary school children in Gambella Regional State, southwestern Ethiopia: A cross sectional study. Parasites Vectors, 8: 215-215. DOI: 10.1186/s13071-015-0822-5

Gray, D.J., A.G. Ross, Y.S. Li and D.P. McManus, 2011. Diagnosis and management of schistosomiasis. BMJ, 342: d2651-d2651. PMID: 21586478

Grimes, J.E., D. Croll, W.E. Harrison, J. Utzinger and M.C. Freeman et al., 2014. The relationship between water, sanitation and schistosomiasis: A systematic review and meta-analysis. PLoS Neglected Tropical Dis., 8: e3296-e3296. DOI: 10.1371/journal.pntd.0003296 
Houmsou, R.S., S.M. Panda, S.O. Elkanah, L.C. Garba and B.E. Wama et al., 2016. Cross-sectional study and spatial distribution of schistosomiasis among children in Northeastern Nigeria. Asian Pacific J. Tropical Biomed., 6: 477-484. DOI: $10.1016 /$ j.apjtb.2016.04.003

Jamison, D.T., J.G. Breman, A.R. Measham, G. Alleyne and M. Claeson et al., 2006. Disease Control Priorities in Developing Countries. 2nd Edn., World Bank Publications, ISBN-10: 0821361805, pp: 1452.

Khalaf, I., A. Shokeir and M. Shalaby, 2012. Urologic complications of genitourinary schistosomiasis. World J. Urol., 30: 31-38. DOI: $10.1007 / \mathrm{s} 00345-011-0751-7$

Magnussen, P., B. Ndawi, A.K. Sheshe, J. Byskov and K. Mbwana et al., 2001. The impact of a school health programme on the prevalence and morbidity of urinary schistosomiasis in Mwera Division, Pangani District, Tanzania. Trans. Royal Society Tropical Med. Hygiene, 95: 58-64. DOI: 10.1016/S0035-9203(01)90333-5

Mafe, M., 1997. The diagnostic potential of three indirect tests for urinary schistosomiasis in Nigeria. Acta Tropica, 68: 277-284.

Mostafa, M.H., S. Sheweita and P.J. O'Connor, 1999. Relationship between schistosomiasis and bladder cancer. Clin. Microbiol. Rev., 12: 97-111.

Negussu, N., M. Wali, M. Ejigu, F. Debebe and S. Aden, et al., 2013. Prevalence and distribution of schistosomiasis in Afder and Gode zone of Somali region, Ethiopia. J. Global Infect. Dis., 5: 149-152. DOI: $10.4103 / 0974-777 X .122007$

Njunda, A.L., E.N. Ndzi, J.C.N. Assob, H.L.F. Kamga and E.T. Kwenti, 2017. Prevalence and factors associated with urogenital schistosomiasis among primary school children in barrage, Magba subdivision of Cameroon. BMC Public Health, 17: 618-618. DOI: 10.1186/s12889-017-4539-6

Omonijo, A., S. Asaolu and I. Ofoezie, 2013. Schistosomiasis transmission and water contact pattern in River Ureje in Ado-ekiti local government area, Ekiti state. Res J. Parasitol., 8: 26-36.
Sady, H., H.M. Al-Mekhlafi, M.A.K. Mahdy, Y.A.L. Lim and R. Mahmud et al., 2013. Prevalence and associated factors of schistosomiasis among children in Yemen: Implications for an effective control programme. PLoS Neglected Tropical Dis., 7: e2377-e2377. DOI: 10.1371/journal.pntd.0002377

Senghor, B., A. Diallo, S.N. Sylla, S. Doucouré and M.O. Ndiath et al., 2014. Prevalence and intensity of urinary schistosomiasis among school children in the district of Niakhar, region of Fatick, Senegal. Parasites Vectors, 7: 5-5. DOI: $10.1186 / 1756-3305-7-5$

Singh, K., D. Muddasiru and J. Singh, 2016. Current status of schistosomiasis in Sokoto, Nigeria. Parasite Epidemiol. Control, 1: 239-244.

DOI: 10.1016/j.parepi.2016.08.003

Uchendu, O., V. Oladoyin, M. Idowu, O. Adeyera and O. Olabisi et al., 2017. Urinary schistosomiasis among vulnerable children in a rehabilitation home in Ibadan, Oyo state, Nigeria. BMC Infect. Dis., 17: 487-487. DOI: $10.1186 / \mathrm{s} 12879-017-2591-6$

Ugbomoiko, U., I. Ofoezie, I. Okoye and J. Heukelbach, 2010. Factors associated with urinary schistosomiasis in two peri-urban communities in south-western Nigeria. Ann. Tropical Med. Parasitol., 104: 409-419. DOI: $10.1179 / 136485910 X 12743554760469$

Ugbomoiko, U.S., V. Dalumo, L., Ariza, F.S.M. Bezerra and J. Heukelbach 2009. A simple approach improving the performance of urine reagent strips for rapid diagnosis of urinary schistosomiasis in Nigerian schoolchildren. Memórias do Instituto Oswaldo Cruz, 104: 456-461.

Uneke, C., P. Oyibo, C. Ugwuoru, A. Nwanokwai and R. Iloegbunam, 2007. Urinary schistosomiasis among school age children in Ebonyi State, Nigeria. Internet J. Laboratory Med., 2: 15-19.

Wamachi, A.N., J.S. Mayadev, P.L. Mungai, P.L. Magak and J.H. Ouma et al., 2004. Increased ratio of tumor necrosis factor- $\alpha$ to interleukin-10 production is associated with Schistosoma haematobium-induced urinary-tract morbidity. J. Infect. Dis., 190: 2020-2030. DOI: $10.1086 / 425579$ 